\title{
A RESEARCH ON PREVALENCE OF LOW BACK PAIN DISABILITY IN MARBLE FACTORY WORKERS
}

KEY WORDS: Work related musculoskeletal disorders, Low back pain, WMSDs, Disability

Dr.Arvind Kumar (PT)

Ph.D. Scholar, M.PT. (Orthopaedics), M.B.A. (Hospital Management), Dean, School Of Physiotherapy, Swarnim Startup \& Innovation University, Gandhinagar, Gujarat, India.

INTRODUCTION:WMSD's among marble factory workers are common. They are a major concern of workers, union, employers and government. Work-related musculoskeletal disorders (MSDs) are disorders of body structures such as tendons, joints, muscles, ligaments, bones, nerves or a local blood circulation system caused or aggravated primarily by the nature of performance of work. The aim of this study was to determine the prevalence of low back pain in marble factory of Aburoad, to know the relation between low back pain and physical activity.

Most work related MSDs are resulting from repeated exposures to low - or high intensity workloads over a prolong period of time. This indicates a strong relationship between factors within the working environment and the development of MSDs, and that these conditions result in significant reduction in productivity

OBJECTIVE: The objective of the study was to study and identify issues and problems of MSDs, specifically LBP. It was believed that results of this study would provide a base for planning interventional programs at work place and improving workers health.

MATERIALS AND METHODS: A questionnaire was formulated with few variables which were specifically focused. A general set of subjective variables such as name, age, sex, occupation, hand dominance, hypertension, weight, BMI were included. Few specific variables were-Nature of job, experience in years, working hours \& overtime, drug addiction (alcohol, tobacco intake),routine of work (sitting/standing/walking/bending/lifting heavy loads), rest time-up to 3 categories(30 minutes $/ 45$ minutes and above)

MATERIALS: It included demographic identification form, modified oswestry disability index of LBP, NPRS sCale, consent form, tapes, Mats etc.

SETTING OFTHE STUDY:Data were collected at 5 marble factories.

PATIENTS: 180 subjects with LBP were involved in the study after screening of approximately 328 workers.

SAMPLING TECHNIQUE: Simple convenient sampling

SAMPLE SIZE: Total 180 subjects of 5 factories with low back pain participated in study.

SELECTION CRITERIA: The study populations were selected according to inclusion/exclusion criteria.

RESULTS: There was a higher prevalence of LBP in factory workers doing more of bending and sitting activities when compared to the standing positions. Even we found that the workers lifting more of heavy weight more than $20 \mathrm{~kg}$ reported of having LBP, which is in concordance to the support etal's study that the workers who had to lift the object up to $25 \mathrm{~kg}$ or more. There were significantly associated with LBP.

CONCLUSION: Work related musculoskeletal disorders in marble factory workers were common as a higher prevalence of LBP. This perception of intensified workloads, repetitive and monotonous work with limited job control and clarity might be one of the factors associated with MSDs. Further research is needed to investigate the effect of risk factors as general health status on prevalence musculoskeletal disorders.

\section{INTRODUCTION-}

The impairments of ligaments, muscles, joints, tendons, nerves, bones, etc. caused by the performance of work are called as work-related musculoskeletal disorders (WSDs). Work-related musculoskeletal disorders are a major public health problem in the industry and also more common in developing countries ${ }^{1,2,3,4,5}$.WMSD's among marble factory workers are common. They are a major concern of workers, unions, employers, and government. Work-related musculoskeletal disorders (MSDs) are disorders of body structures such as tendons, joints, muscles, ligaments, bones, nerves or a local blood circulatory system.

Work-related physical handling of materials, especially heavy load lifting, frequent bending, twisting, working in awkward postures and vibration of whole-body, are wellestablished risk factors for $\mathrm{LBP}^{6,7}$

Improper body movements such as manual handling, working in sitting, bending, lifting heavy loads etc. is directly related to prevalence of LBP.

Evidence showed that in the period 2004-2005, 11 million days of work were lost because of musculoskeletal disorders in the U.K. ${ }^{4}$

These disorders are cumulative once resulting from exposure to high and low-intensity loads over a long period of time. The major factor contributing to musculoskeletal disorders is poor working posture resulting in a minor to a severe back problem.

There are various risk factors known to be included in workplace activities such as heavy load lifting, repetitive task, and awkward working postures as well as the nature of job cutting shearing drilling, etc. caused or aggravated primarily by the nature of the performance of work. ${ }^{8}$

Low back pain is not life threatening disorder but it has a long term impact on expenditures for affected workers. ${ }^{9}$

The aim of this study was to determine the prevalence of low back pain in the marble factory of Aburoad city and to know the relation between low back pain and physical activity.

Most work-related MSDs are resulting from repeated exposures to low - or high-intensity workloads over a prolong period of time. This indicates a strong relationship between factors within the working environment and the development of MSDs, and that these conditions result in a significant reduction in productivity. ${ }^{10}$

Approximately 100 million occupational disorders are occurring throughout the world annually. ${ }^{11,12}$

Marble is commonly used in the sculpturing of the statue, the construction of buildings and monument. ${ }^{13}$ 
The workers in the marble factory are involved in awkward posture and long hours of standing work.

Epidemiological data concerning WMSD are usually available in industrially developed countries. So we preferred study setting, which is also an industrial area and where ample amount of marble factories are available and Aburoad has opted for such a study setting.

Many studies have been conducted in various developed countries, in a large European survey showed that $45 \%$ of 130 million population workers were exposed to manual material handling and awkward postures.

Another study conducts in Iranian Communication Company showed a significant association between job tenure and MSD in the lower back region as well.

The aim of this study justifies on the prevalence of musculoskeletal disorders in marble factory workers, which can contribute to more effective strategic planning in the country.

Many active workers have musculoskeletal disorders as discomfort or pain may become incompatible which may lead to sick leave.

This study in active suspected workers who have minor problems -may help prevent the progression of the disease.

\section{OBJECTIVE:}

The objective of the study was to study and identify issues and problems of MSDs; specifically LBP. To assess occupational risk factors related to the prevalence of LBP It was believed that the results of this study would provide a base for planning interventional programs at the workplace and improving workers health.

\section{INCLUSION CRITERIA:}

Age: - 20-60

Gender:-Both male and female

Completing a minimum of 3 months period of occupation

Workers involved in sitting and standing activities

Nature of job involving bending and lifting activities

Good communication activities

Working hours more than 7

\section{EXCLUSION CRITERIA:-}

Acute health condition

Cancer

$\mathrm{RA}$

Any health conditions that could alter the perception of pain TB

Workers who involve in washing, cleaning activities

\section{OUTCOME MEASURE:-}

MODI

NPRS

\section{MATERIALS AND METHODS:-}

A questionnaire was formulated with few variables which were specifically focused.

A general set of subjective variables such as name, age, sex, occupation, hand dominance, hypertension, weight, BMI were included. Few specific variables were-Nature of job, experience in years, working hours \& overtime, drug addiction (alcohol, tobacco intake), a routine of work (sitting/standing/walking/bending/lifting heavy loads), rest time-up to 3 categories ( 30 minutes $/ 45$ minutes and above).

Data were collected at 5 marble factories in Aburoad between February to March 2018.

|www.worldwidejournals.com|
The objective of the study is to "Study and identify the issues and problems of MSD" that to specifically LBP. It is believed that the results of this study would provide a base for planning interventional programs at the workplace and improving workers health.

\section{MATERIALS: -}

It included demographic identification form, modified Oswestry disability index of LBP, NPRS scale, consent form, tapes, Mats, etc.

\section{SETTING OFTHE STUDY:-}

Data were collected at 5 marble factories.

\section{PATIENTS:-}

180 subjects with LBP were involved in the study after a screening of approximately 328 workers.

\section{SAMPLING TECHNIQUE:-}

Simple convenient sampling

\section{SAMPLE SIZE:-}

A total of 180 subjects of 5 factories with low back pain participated in the study.

\section{SELECTION CRITERIA:-}

The study populations were selected according to inclusion/exclusion criteria.

\section{RESULTS:-}

The prevalence of LBP was found to be $54.87 \%$. There was a higher prevalence of LBP in factory workers doing more of bending and sitting activities when compared to the standing positions. Even we found that the workers lifting more of heavyweight more than $20 \mathrm{~kg}$ reported having LBP, which are in concordance to the Supreet et al's study that the workers who had to lift the object up to $25 \mathrm{~kg}$ or more. There were significantly associated with LBP and that to 1.27 times more frequently

\section{Table 1: Give $F$ and $F \%$ of $A G E$}

\begin{tabular}{|l|l|l|}
\hline AGE & F & F\% \\
\hline $20-29$ & 9 & 5 \\
\hline $30-39$ & 51 & 28.33333 \\
\hline $40-49$ & 15 & 8.333333 \\
\hline $50-59$ & 104 & 57.77778 \\
\hline $60-69$ & 1 & 0.555556 \\
\hline TOTAL & 180 & 100 \\
\hline
\end{tabular}

Table 2: Association with nature of work shows, those who are involved in cutting shows less MOLBPQ(41 People)

\begin{tabular}{|c|c|c|c|c|c|}
\hline \multicolumn{2}{|c|}{} & \multicolumn{4}{c|}{ Nature of work } \\
\cline { 2 - 6 } \multicolumn{2}{|c|}{} & CUTTING & DRILL & GRIND & SHEAR \\
\hline \multirow{2}{*}{$\begin{array}{l}\text { MOL } \\
\text { BPQ }\end{array}$} & $>$ Median & 19 & 19 & 37 & 12 \\
\cline { 2 - 6 } & $<=$ Median & 41 & 22 & 21 & 9 \\
\hline \multirow{2}{*}{ <PRS } & $>$ Median & 9 & 11 & 16 & 6 \\
\cline { 2 - 6 } & $<=$ Median & 51 & 30 & 42 & 15 \\
\hline
\end{tabular}

Table 3: Association with nature of work shows, there is significant association between MOLBPQ and nature of work because $\mathbf{P}=\mathbf{0 . 0 0 5}$ which is less than 0.05 .

\begin{tabular}{|c|c|c|}
\hline & MOLBPQ & NPRS \\
\hline $\mathrm{N}$ & 180 & 180 \\
\hline Median & 34.0000 & 4.0000 \\
\hline Chi-Square & $12.943 \mathrm{~b}$ & $3.518^{\mathrm{c}}$ \\
\hline P-VALUE & $.005 \mathrm{SIG}$ & $.318 \mathrm{NS}$ \\
\hline
\end{tabular}

Table 4:No significant association between MOLBPQ, NPRS with experience

\begin{tabular}{|c|c|c|}
\hline & MOLBPQ & NPRS \\
\hline Median & 36.0000 & 4.0000 \\
\hline Chi-Square & $.312^{\mathrm{b}}$ & $2.076^{\mathrm{c}}$ \\
\hline P-VALUE.. & $.856 \mathrm{NS}$ & $.354 \mathrm{NS}$ \\
\hline
\end{tabular}


Table 5:There is significant association with routine of work and MOLBPQ. , above table shows. Those who involved in bending are having high MOLBPQ and NPRS.

\begin{tabular}{|c|c|c|}
\hline & MOLBPQ & NPRS \\
\hline Median & 34.0000 & 4.0000 \\
\hline Chi-Square & $53.780^{\mathrm{b}}$ & $35.929^{\mathrm{c}}$ \\
\hline P-VALUE.. & .000 SIG & .000 SIG \\
\hline
\end{tabular}

\section{ASSOCIATION MOLBPQ,NPRSWITH REST TIME}

Table 6: No significant association between MOLBPQ, NPRS with REST TIME.

\begin{tabular}{|c|c|c|}
\hline & MOLBPQ & NPRS \\
\hline Median & 34.0000 & 4.0000 \\
\hline Chi-Square & $2.906^{\mathrm{b}}$ & $5.897^{\mathrm{c}}$ \\
\hline P-VALUE. & $.234 \mathrm{NS}$ & $.052 \mathrm{NS}$ \\
\hline
\end{tabular}

\section{DISCUSSION:-}

This study describes the prevalence and risk factors for LBP among marble industry workers. More than $80 \%$ of the population experience LBP at some time during their lives. The prevalence of MSWDS among industry workers who usually are in full working activity is high. There are very few studies identified the prevalence of musculoskeletal pain among marble factory workers in India. Similarly, one study was conducted among dentists using questionnaires sent by mail with a prevalence rate of $58 \%$. Similarly, another study conducted by Ardiana Murtezani et.al. mentioned a low back pain prevalence of $61.6 \%$ among industrial workers which is consistent with most of the epidemiological studies investigating over the year LBP prevalence in workers. The possible cause of this rising prevalence is due to the time spent by workers in a seated position or frequently turning and twisting torso and exposure to awkward postures, vibration, and load lifting.

Literature shows that manual handling, frequent bending, twisting, heavy load lifting, repetitive tasks, and heavy physical work are the risk factors for WMSD especially LBP. ${ }^{14,15}$ Another study conducted by Supreet et.al. in India mentioned that the increasing age doubles the risk of having LBP and they found a higher prevalence in the age group of 30-40 and $50-60$ years.

According to them the jobs involved in lifting or moving weights of $25 \mathrm{kgs}$ or more have been found to have strong occupational associations with LBP. Work activities such as lifting, pulling, pushing, sitting and bending were highly associated with LBP (Anannont sak et al 1996).

This perception of intensified workloads, repetitive and monotonous work with limited job control and clarity might be one of the factors associated with MSD.

Almost similar results were found in our study as well, there was a higher prevalence of LBP in factory workers doing more of bending and sitting activities when compared to the standing position. Even we found that the workers lifting more of heavyweight i.e. more than $20 \mathrm{~kg}$ reported of having LBP, which are in concordance to the Supreet et al's study that the workers who had to lift the object up to $25 \mathrm{~kg}$. or more there were significantly associated with LBP and that too 1.27 times more frequently.

Most of the marble factory workers affected by LBP were age group between 30-39 \& 50-59 years, Mostly sufferer ware doing sitting job.

\section{CONCLUSION}

Work-related musculoskeletal disorders in marble factory workers were common as a higher prevalence of LBP. This perception of intensified workloads, repetitive and monotonous work with limited job control and clarity might be one of the factors associated with MSDs. Further research is needed to investigate the effect of risk factors as general health status on prevalence musculoskeletal disorders.

\section{CONFLICT OF INTEREST:-None}

SOURCE OF FUNDING:-Self

ETHICAL CLEARANCE:-Has taken from Ethical committee

\section{REFERENCES}

[1]. National Research Council/Institute of Medicine. Musculoskeletal disorders and the workplace:low back and upper extremities. Washington DC:National Academy Press;2001.

[2]. Melhorn JM. Cumulative trauma disorders and repetitive strain injuries. The future. Clin Orthop Relat Res 1998;351:107-26.

[3]. Melhorn JM, Gardner P. How we prevent the prevention of musculoskeletal disorders in the workplace. Clin Orthop 2004; 419:285-96.

[4]. European Agency for Safety and Health at Work. Work-related musculoskeletal disorders: back to work report. Luxembourg: Office for Official Publications of the European Communities; 2007.

[5]. Marras WS, Cutlip RG, Burt SE, Waters TR. National occupational research agenda (NORA) future directions in occupational musculoskeletal disorder health research. Appl Ergon 2009; 40:15-22.

[6]. Tamrin SBM, Yokoyama K, Jalaludin J, et al. The associations between risk factors and low back pain among commercial vehicle drivers in Peninsular Malaysia. Ind Health 2007;45(2):268-78.

[7]. Miranda H, Viikari-Juntura E, Punnett L, Riihimaki H. Occupational loading, health behavior and sleep disturbance as a predictor of low-back pain. Scand JWork Environ Health 2008;34(6):411-9.

[8]. Bernard B. Washington, DC: U.S. Government Printing Office; 1997. Musculoskeletal disorders and workplace factors: A critical review of epidemiologic evidence for work-related musculoskeletal disorders of the neck, upper extremity, and low back. (DHHS/NIOSH publication no 97-141)

[9]. Leboeuf-yde, C, kyvik,k.At what age does low back pain become a common problem? A study of 29434 individuals aged $12-41$ years .spine 1998;23:228234.

[10]. Buckle P, Devereux J. (1999) Work-Related Neck and Upper Limb Musculoskeletal Disorders. Bilbao, Spain: European Agency for Safety and Health atWork.

[11] Leigh J, Macaskill P, Kuosma E and Mandryk J (1999). Global burden of disease and injury due to occupational factors. Epidemiology, 10:626-631.

[12] Dzissah J, Karwowski W and Yang YN (2001). Integration of Quality, Ergonomics, and Safety Management Systems. In Karwowski W (ed): International Encyclopedia of Ergonomics and Human Factors. London: Taylor and Francis, pp. 1129-1135.

[13]. Corinaldesi, V., Moriconi, G. and Naik T. R. "Characterization of Marble Powder for its use in Mortar and Concrete". Const. Build. Mat. 2010;24: 113117.

[14]. Elders LAM, Burdorf A. Interrelations of risk factors and low back pain in scaffolders. Occup Environ Med 2001;58:597-603

[15]. Andrusaitis SF, Oliveira RP, Eloy T, FilhoB. Study of the prevalence and risk factors for low back pain in truck drivers in the state of Sao Paulo, Brazil. Clinics 2006:61(6):503-10 